\title{
Communication to the Editor
}

\section{Expanding the Chinese hamster ovary cell long non-coding RNA transcriptome using RNASeq}

Krishna Motheramgari ${ }^{1,2 \dagger}$, Ricardo Valdés-Bango Curell ${ }^{2 \dagger}$, Ioanna Tzani $^{1}$, Clair Gallagher ${ }^{2}$, Marina Castro Rivadeneyra ${ }^{1,3}$, Lin Zhang $^{4}$, Niall Barron ${ }^{1,3}$ and Colin Clarke ${ }^{1,3 \dagger_{*}}$

${ }^{1}$ National Institute for Bioprocessing Research and Training, Fosters Avenue, Blackrock, Co. Dublin, Ireland.

${ }^{2}$ National Institute for Cellular Biotechnology, Dublin City University, Glasnevin, Dublin 9, Ireland.

${ }^{3}$ School of Chemical and Bioprocess Engineering, University College Dublin, Belfield, Dublin, Ireland.

${ }^{4}$ Bioprocess R\&D, Pfizer Inc., Andover, Massachusetts, USA

${ }^{\dagger}$ Equal contribution

* Corresponding author

Email: colin.clarke@nibrt.ie

Phone: +353 12158164

Fax: +35312158116

Keywords: Chinese hamster ovary, long non-coding RNA, RNASeq, transcriptomics, temperature shift, next generation sequencing

Abbreviations: Chinese hamster ovary (CHO); long non-coding RNA (IncRNA); next generation RNA sequencing (RNASeq); Benjamini Hochberg (BH); false discovery rate (FDR); Kolmogorov-Smirnov (KS); monoclonal antibody (mAb) 


\begin{abstract}
Our ability to study Chinese hamster ovary $(\mathrm{CHO})$ cell biology has been revolutionised over the last decade with the development of next generation sequencing and the publication of reference DNA sequences for $\mathrm{CHO}$ cells and the Chinese hamster. RNA sequencing has not only enabled the association of transcript expression with bioreactor conditions and desirable bioprocess phenotypes but played a key role in the characterisation of protein coding and small non-coding RNAs. The annotation of long non-coding RNAs, and therefore our understanding of their role in $\mathrm{CHO}$ cell biology, has been limited to date. In this manuscript, we use high resolution RNASeq data to more than double the number of annotated IncRNA transcripts for the CHOK1 genome. In addition, the utilisation of strand specific sequencing enabled the identification of more than 1,000 new IncRNAs located antisense to protein coding genes. The utility of monitoring IncRNA expression is demonstrated through an analysis of the transcriptomic response to a reduction of cell culture temperature and identification of simultaneous sense/antisense differential expression for the first time in $\mathrm{CHO}$ cells. To enable further studies of IncRNAs, the transcripts annotated in this study have been made available for the $\mathrm{CHO}$ cell biology community.
\end{abstract}

In recent years, successful cell line engineering strategies to enhance the production of recombinant therapeutic proteins in Chinese hamster ovary $(\mathrm{CHO})$ cells through the modulation of mRNA and noncoding RNAs, such as microRNAs (miRNAs), have been reported by academic and industrial research groups (Fischer, Handrick, \& Otte, 2015). As new avenues for genetic manipulation continue to be explored, long non-coding RNAs (IncRNAs), defined as transcripts longer than 200 nucleotides that do not encode a protein, have emerged as a potential route for rational design of $\mathrm{CHO}$ cell factories (Vito \& Smales, 2018). These non-coding RNAs elicit their function through a diverse array of mechanisms including recruiting epigenetic modifying complexes to genomic loci or acting as mimics that sequester proteins or miRNAs (Fang \& Fullwood, 2016). IncRNAs have been shown to interact with RNA, DNA or protein and play regulatory roles in the transcription and translation of nearby (cis) or distant (trans) genes. Functional studies in other species have revealed the importance of IncRNAs in cellular processes such as proliferation (Liu et al., 2017) and the interest in manipulating IncRNAs for improving $\mathrm{CHO}$ cell bioprocess performance has increased. A recent study has shown that sequence elements can also be derived from long coding RNA and be utilised to build constructs to increase recombinant protein production (Patrucco et al., 2015).

Despite the availability of several reference genomes for $\mathrm{CHO}$ cells (Lewis et al., 2013; Rupp et al., 2018; Xu et al., 2011) and tremendous improvements in transcriptome characterisation, IncRNAs remain poorly annotated severely limiting our ability to associate these molecules with bioprocess phenotypes, and consequently, their utility for cell line engineering. Of the three reference genomes currently available through Ensembl (release 98), the CHOK1 genome contains the largest number of annotated IncRNA genes, yet this number represents only $19 \%$ and $14 \%$ of the total number of 
mouse (v23) and human (v32) IncRNAs annotated in GENCODE respectively (Frankish et al., 2019). The poor conservation of IncRNAs across species and our lack of understanding of their defining sequence features in comparison to protein coding genes present considerable challenges. Next generation sequencing has, however, proven to be an important tool for IncRNA discovery in nonmodel organisms (Uszczynska-Ratajczak, Lagarde, Frankish, Guigó, \& Johnson, 2018). In this manuscript, we describe the utilisation of high-resolution RNA sequencing (RNASeq) to significantly expand the $\mathrm{CHO}$ cell IncRNA landscape and subsequently demonstrate that changes in the bioreactor environment can alter the expression of these molecules.

The RNASeq data utilised for this analysis was generated as part of a study in our laboratory to advance our understanding of the transcriptomic response to decreasing $\mathrm{CHO}$ cell culture temperature (i.e. "temperature shift") (see Tzani et al. submitted to Biotechnology \& Bioengineering for details). Briefly, the experimental design of the study involved growing 8 biological replicates of a monoclonal antibody (mAb) producing $\mathrm{CHOK} 1$ cell lines for $48 \mathrm{hrs}$ at $37^{\circ} \mathrm{C}$. The temperature of 4 replicates was then reduced to $31^{\circ} \mathrm{C}$ while the remaining 4 replicates were maintained at $37^{\circ} \mathrm{C}$ before all samples were submitted for transcriptomic analysis at $24 \mathrm{hrs}$ post temperature shift. The transition to sub-physiological cell culture temperature resulted in a reduction of growth rate, alteration of extracellular metabolite concentration as well as widespread changes in mRNA abundance and splicing (see Tzani et al. submitted to Biotechnology \& Bioengineering).

The RNASeq data acquired is ideally suited for IncRNA discovery and expression analysis as a result of (1) the elimination of rRNA from total RNA prior to library preparation via subtractive hybridisation rather than enriching for RNAs with a polyA tail, (2) the preparation of sequencing libraries using a strand-specific method to capture IncRNAs expressed from the opposite strand to protein coding genes (i.e. antisense) and (3) capturing $>50$ million $150 \mathrm{bp}$ paired-end reads for each sample to ensure sufficient sampling depth for accurate detection and assembly of lower abundance IncRNA transcripts. To identify IncRNAs from these data a rigorous computational pipeline incorporating transcriptome assembly, IncRNA discovery methods, comparative genomics and comparison to coding and non-coding sequence databases was implemented (Figure 1). 
bioRxiv preprint doi: https://doi.org/10.1101/863241; this version posted December 3, 2019. The copyright holder for this preprint (which was not certified by peer review) is the author/funder, who has granted bioRxiv a license to display the preprint in perpetuity. It is made available under aCC-BY-NC-ND 4.0 International license.

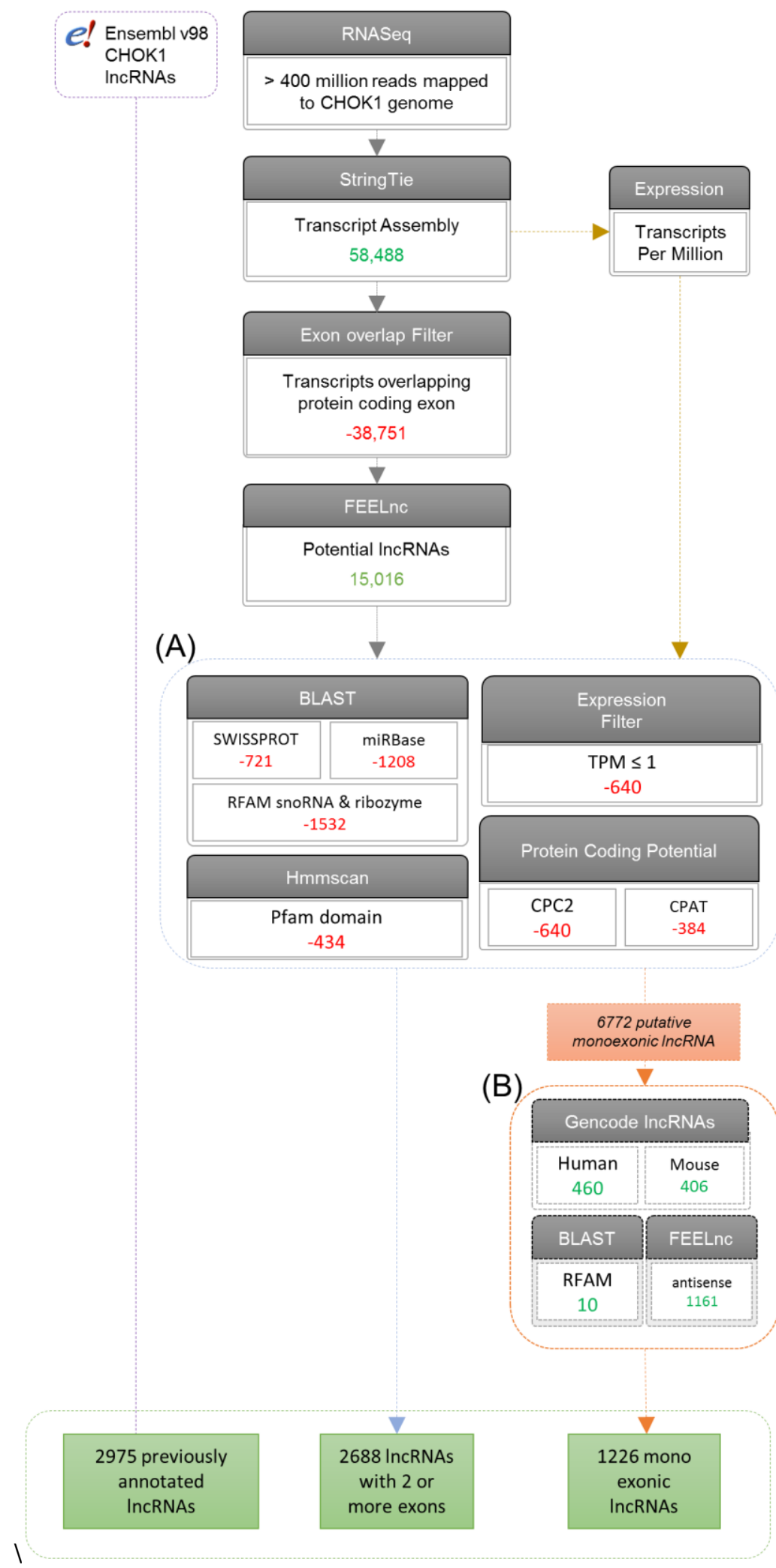

Figure 1: Overview of the CHO cell long non-coding RNA annotation pipeline. To accurately identify IncRNAs from the RNASeq data high quality reads mapped to the Ensembl CHOK1 genome were utilised to construct a genome guided assembly using StringTie. All transcripts that intersected with an exon of annotated protein coding genes were eliminated before FEELnc was utilised to identify putative IncRNAs. (A) The first filtering stage removed the FEELnc predicted IncRNA transcripts that had significant hits with non-IncRNA transcripts or protein databases. In addition, transcripts with TPM $\leq 1$ or were not predicted as non-coding by CPC2 and CPAT were also removed. (B) The second classification stage was utilised to retain only those single IncRNAs that were orthologous with human or mouse, present in RFAM or were found on the opposite strand to an annotated protein coding gene. In total, 3,599 IncRNAs not annotated in ENSEMBL were identified bringing the total number of IncRNAs annotated for CHOK1 to 6,598. 
During the initial stage of bioinformatics analysis, $>400 \mathrm{M}$ combined high quality mappable RNASeq reads from the 8 samples were utilised to assemble $>58,000$ transcripts using StringTie (Pertea et al., 2015). Following the removal of $>38,000$ transcripts intersecting same-strand exons of protein coding genes, 19,737 transcripts were analysed using the FLExible Extraction of Long non-coding RNAs (FEELnc) IncRNA discovery algorithm (Wucher et al., 2017). FEELnc first eliminates transcripts shorter than 200 nucleotides before assigning a protein coding potential score to the remaining transcripts (the likelihood a particular transcript encodes a protein coding gene). The 15,016 putative IncRNAs identified by FEELnc were further reduced by retaining only those also determined to be non-coding by both the CPC2 and CPAT methods, found not to contain a PFAM protein domain and did not have either a significant BLAST hit against SWISSPROT, miRBase or RFAM snoRNA and ribozyme families (Figure 1A). Of the 9,410 transcripts remaining after this first-pass filtering stage, 2,688 IncRNAs with 2 or more exons were identified while the remainder were putative single exon IncRNAs. To increase the stringency of our analysis and eliminate potential false positives, only the 1,266 monoexonic IncRNAs that were antisense to protein coding gene, present in RFAM or orthologous to GENCODE annotated IncRNAs in either human or mouse were retained (Figure 1B). This analysis has resulted in the identification of 3,588 novel IncRNA transcripts and reclassification of 35 RNAs annotated as miscRNAs or pseudogenes in Ensembl (for instance, 5 of these RNAs fall below the 200bp definition of a long non-coding RNA, but were extended in our transcriptome assembly). These new IncRNAs, when combined with those currently available in Ensembl, bring the total number annotated for the CHOK1 cell line to 6,598 IncRNAs.

Comparison of the expanded IncRNA transcriptome to protein coding genes revealed that, as others have observed previously (Derrien et al., 2012), IncRNAs are generally shorter (Kolmogorov-Smirnov $(\mathrm{KS})$ test $\mathrm{p}$-value $\left.=<2 \times 10^{-16}\right)($ Figure $2 \mathrm{~A})$, less abundant (KS test $\mathrm{p}$-value $=<2 \times 10^{-16}$ ) (Figure 2B), and have a lower GC content than mRNAs (KS test p-value $=<2 \times 10^{-16}$ )(Figure 2C). CHO cell IncRNA genes also tended to be comprised of fewer exons (Figure 2D) and express fewer isoforms (Figure $2 \mathrm{E}$ ) in comparison to protein coding genes, although the difference is less pronounced than observations in human and mouse due to comparatively poorer annotation of $\mathrm{CHO}$ cell mRNA isoforms. Intergenic IncRNAs (defined as those $>100 \mathrm{~kb}$ from a protein coding gene) were found to be the most prevalent $(n=1,982)$ following analysis of IncRNA genomic organisation with respect to protein coding genes (Figure 2F). In addition, a dramatic increase in the number of antisense (defined 
bioRxiv preprint doi: https://doi.org/10.1101/863241; this version posted December 3, 2019. The copyright holder for this preprint (which was not certified by peer review) is the author/funder, who has granted bioRxiv a license to display the preprint in perpetuity. It is made available under aCC-BY-NC-ND 4.0 International license.

as overlapping a protein coding gene on the opposite strand of DNA) $(n=1,376)$ and antisense divergent IncRNAs (defined as $\leq 2 \mathrm{~kb}$ upstream of the protein gene) was identified $(\mathrm{n}=359)$.

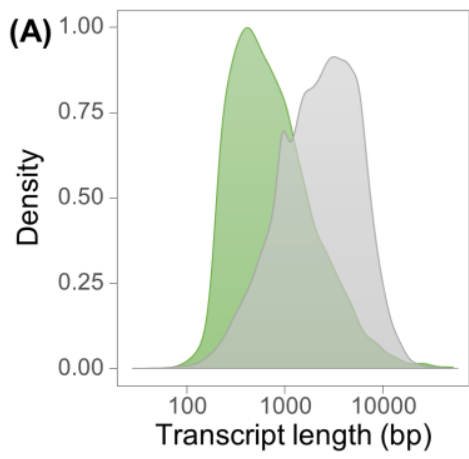

(D)

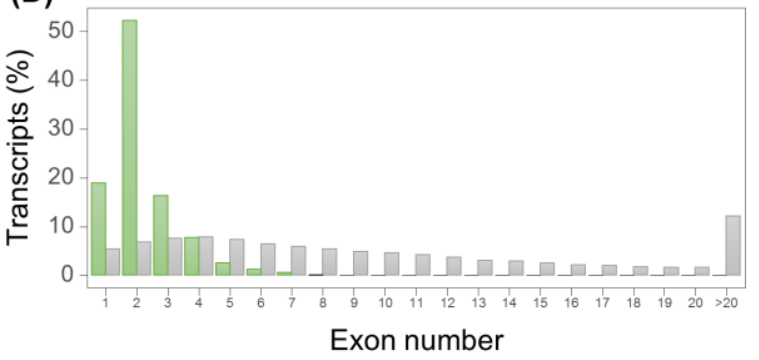

(F)

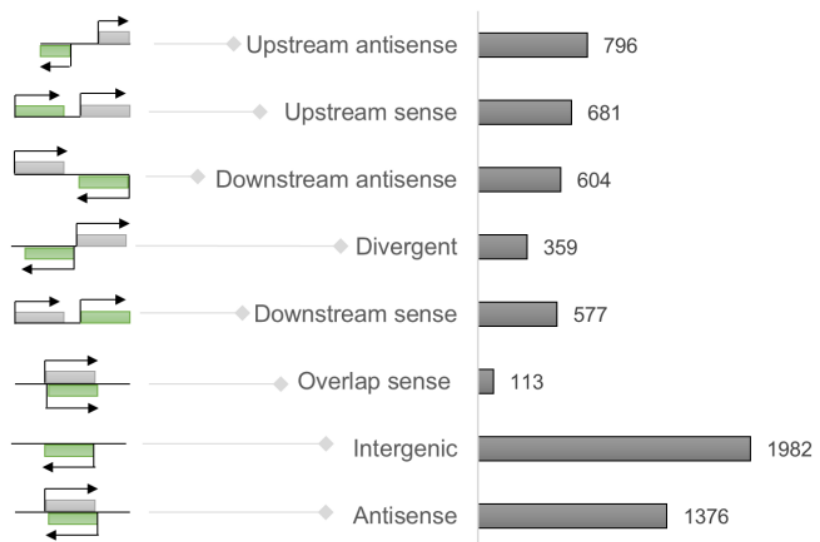

(E)
(B)

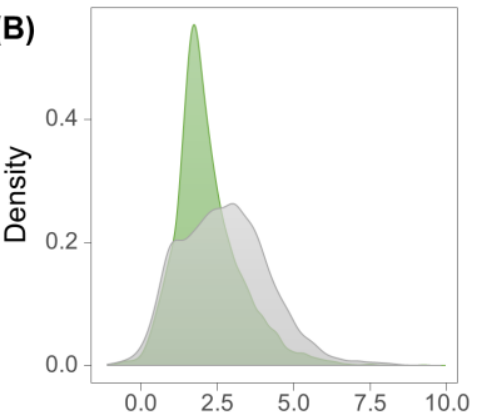

Transcript expression $\log _{2}($ TPM+1)

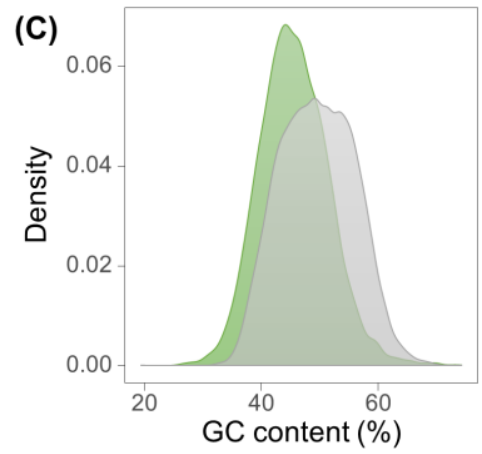

IncRNA $\square$ mRNA
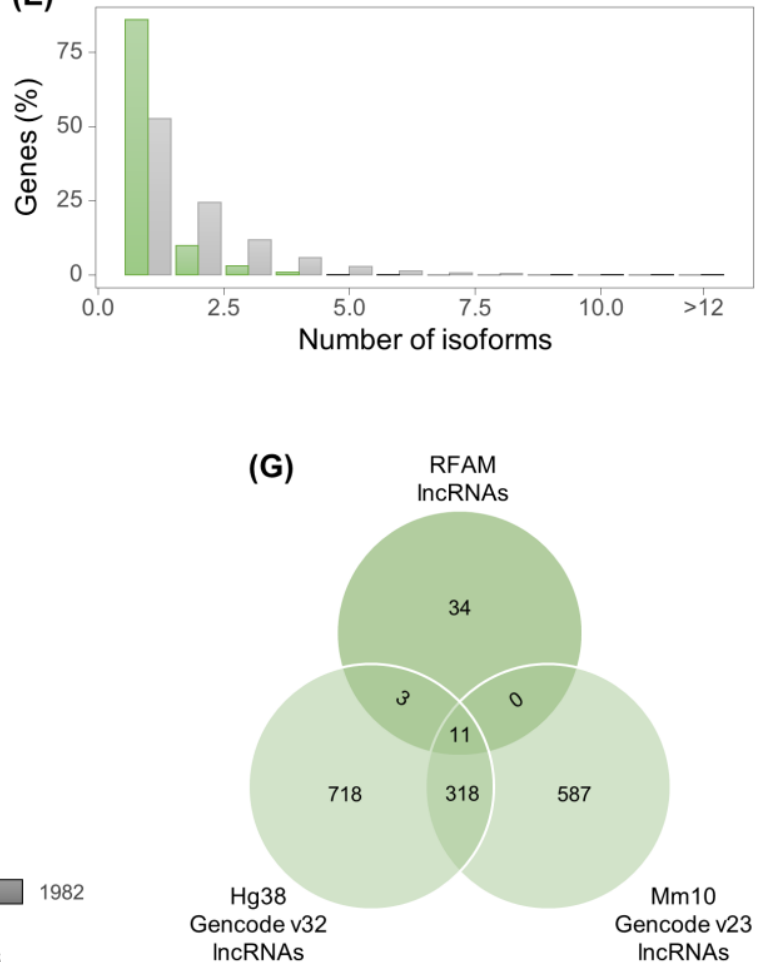

Figure 2: Comparison of IncRNA transcripts to annotated protein coding genes. Following comparison of the 6,598 IncRNAs annotated for CHOK1 cells to mRNA transcripts annotated in ENSEMBL, IncRNAs tend to be (A) shorter, (B) expressed at lower abundance and of generally (C) lower GC content. In addition, IncRNA transcripts had (D) a lower number of exons and (E) transcripts per gene. Following the determination of CHOK1 IncRNAs with respect to protein coding genes (F) intergenic and antisense IncRNAs were the two most prevalent classes. Sense overlap IncRNAs are likely to be underestimated due to the limitations of using RNASeq and further methods will be required to accurately annotate this type of IncRNA. The lower cross species conservation of IncRNAs is (G) indicated by a small number of transcripts returning significant hits from following a BLAST search against RFAM in comparison to the number of syntenic IncRNAs identified in the human and mouse genomes.

The least frequent class was found to be sense overlapping $(n=113)$ although the conservative approach to annotation taken in this study will undoubtedly have decreased the number of these IncRNA identified. $13.8 \%$ and $15.9 \%$ of IncRNAs were found to be orthologous to IncRNA gene loci in human and mouse respectively (Figure 2G). While well-known genes including Malat1, had significant 
BLAST hits against RFAM, <1\% CHOK1 IncRNAs (both novel and in Ensembl) were identified confirming the lower cross-species conservation of IncRNA sequences.

Following completion of the annotation phase, we sought to determine if long non-coding RNA abundance was changed following temperature shift of a mAb producing $\mathrm{CHO}$ cell line. For this analysis we utilised replicate data from both conditions and performed a gene-level count based differential expression analysis for the complete StringTie transcriptome assembly (IncRNAs and other RNAs were included in this step). The abundance of 400 IncRNAs (223 upregulated, 177 downregulated) were found to be significantly altered by $\geq \pm 1.5$ fold change (FC) $24 \mathrm{hrs}$ after the reduction of cell culture temperature to $31^{\circ} \mathrm{C}$ (Benjamini Hochberg $(\mathrm{BH})$ adjusted $\mathrm{p}$-value $<0.05$ ) (Figure 3A) (Table S1). The most frequent class of differentially expressed IncRNAs were intergenic RNAs ( $n=114$ ), followed closely by antisense IncRNAs ( $n=94)$. Of the 327 differentially expressed IncRNAs unannotated in Ensembl, 176 orthologs were identified from GENCODE IncRNAs annotations for either the human or mouse genome.

(A)

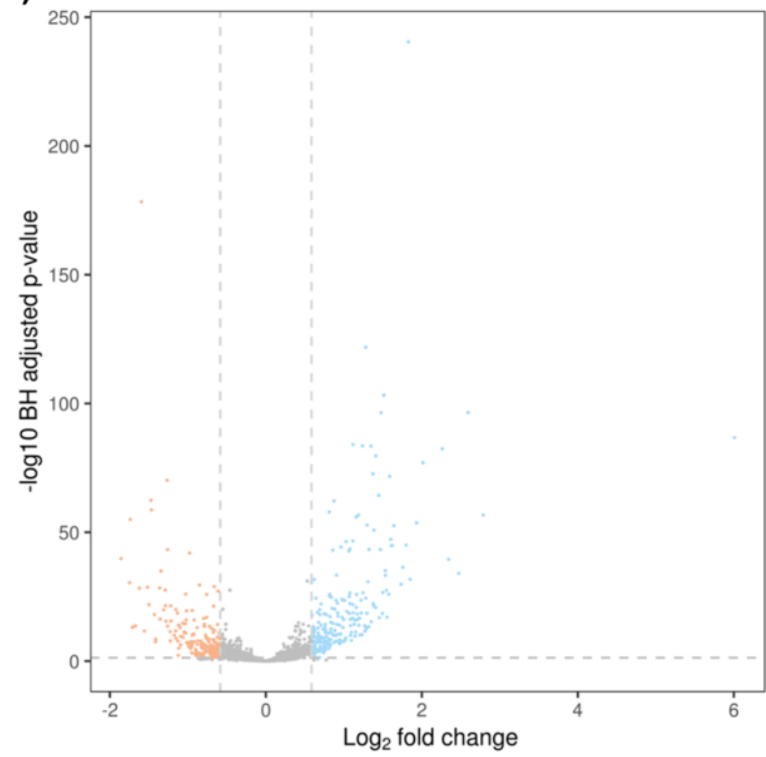

(B)

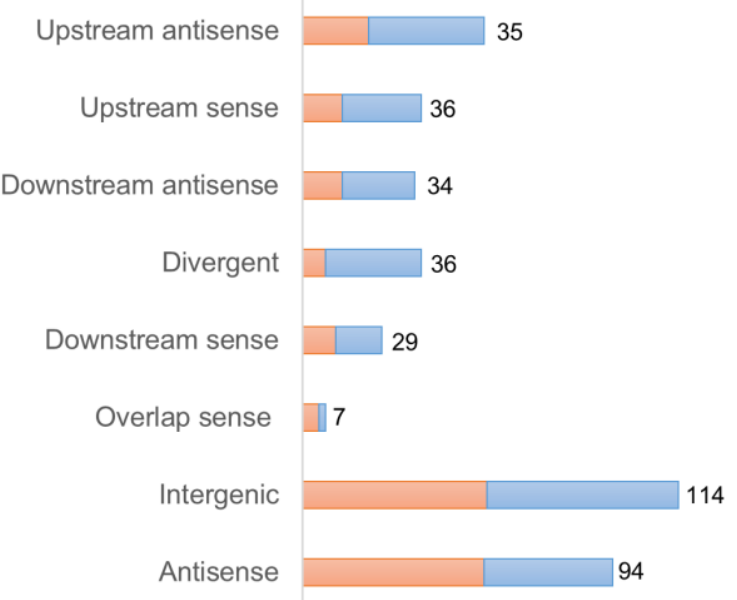

Figure 3: CHO cell temperature shift induces differential expression of IncRNAs. Following a reduction of cell culture temperature (A) the abundance of 400 IncRNAs changed were significantly altered $24 \mathrm{hrs}$ post-temperature shift with (B) 94 antisense IncRNAs found to be differentially expressed.

Next, we compared the 400 differentially expressed IncRNAs to the 1,317 differentially expressed protein coding genes identified from the same dataset using an identical count-based gene level analysis (see Tzani et al.). Twenty-one differentially expressed protein coding genes were found to have to have an overlapping antisense IncRNA or antisense IncRNA within 2kb upstream (divergent) 
bioRxiv preprint doi: https://doi org/10.1101/863241; this version posted December 3, 2019. The copyright holder for this preprint (which was not certified by peer review) is the author/funder, who has granted bioRxiv a license to display the preprint in perpetuity. It is made available under aCC-BY-NC-ND 4.0 International license.

that was aslo differentially expressed. 10 of these sense/antisense protein-coding/IncRNA gene pairs were found to be correlated (i.e. both the IncRNA and mRNA were upregulated) while the remaining 11 were found to be anticorrelated (i.e. the IncRNA was downregulated while the mRNA was upregulated). While these positively and negatively correlated differences in expression for protein coding and IncRNA gene pairs are certainly intriguing, these changes could occur independently (Goyal et al., 2017) and further research is required to confirm regulatory interactions.

(A)

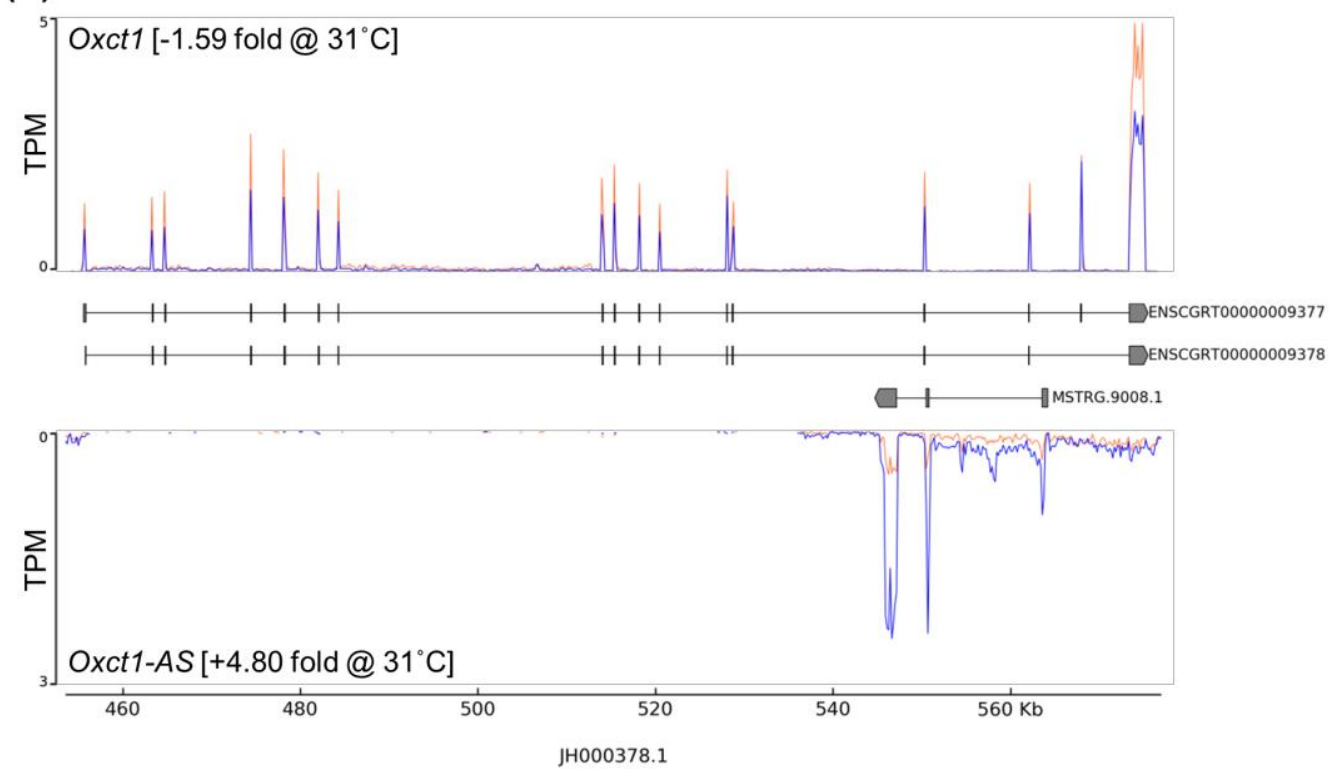

(B)
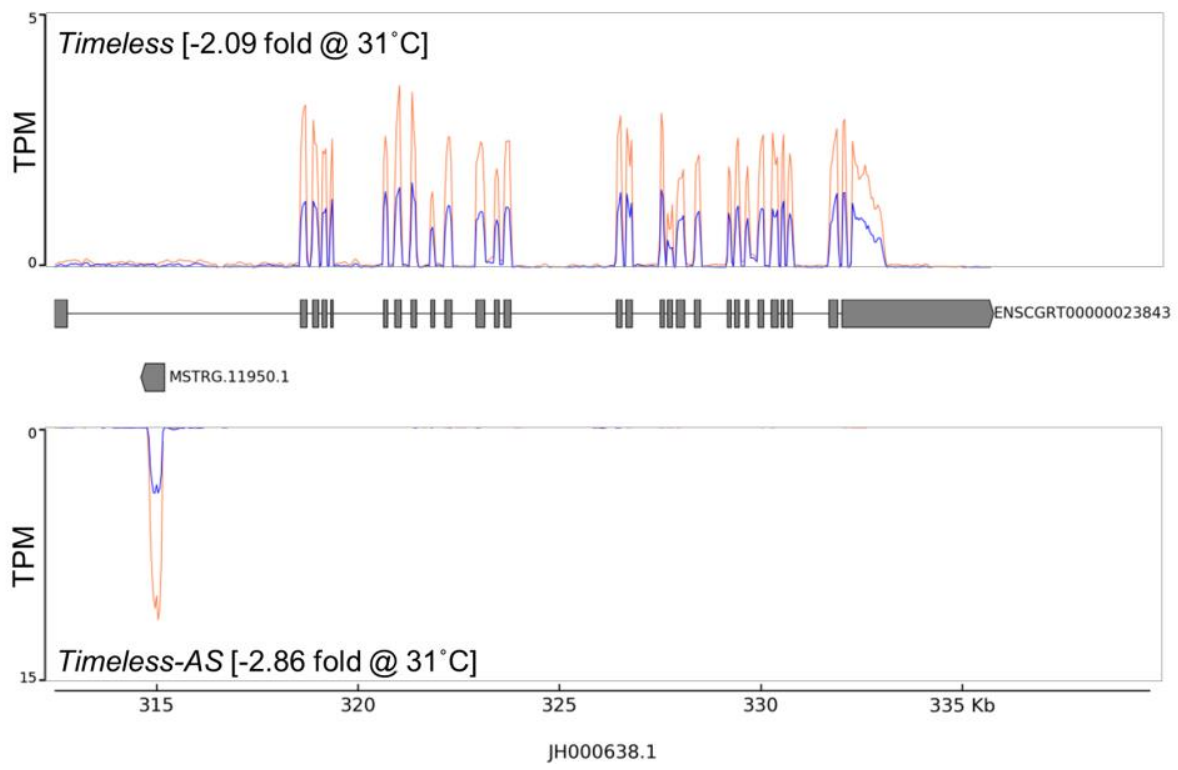

Figure 4: Differential expression of antisense $\mathrm{CHO}$ cell IncRNAs can be negatively or positively correlated to the partner mRNA found on the opposite strand. The mean TPM RNASeq coverage of the 4 biological replicates for the temp shifted (blue) and non-temperature shifted samples (orange) The (A) Oxct1 gene locus is shown for both the sense and antisense strands. The expression of Oxct1 decreases following the transition to $31^{\circ} \mathrm{C}$ while the expression of the Oxct1-AS IncRNA increases. In contrast (B) the Timeless mRNA and the Timeless-AS IncRNA were both found to decrease following temperature shift 
In summary, the results of this study have significantly expanded the number of IncRNAs annotated for $\mathrm{CHO}$ cells, We have demonstrated that that IncRNA expression is altered upon a reduction of cell culture temperature and in some cases that both protein coding genes and IncRNA located in close proximity on the antisense strand can undergo correlated or anticorrelated changes in expression. More than $80 \%$ of the differentially expressed IncRNAs identified in this study are not currently annotated in Ensembl highlighting the importance of improving the characterisation of these molecules if we are to understand the role of IncRNAs in $\mathrm{CHO}$ cells during the production of recombinant therapeutic proteins. While much work remains to uncover the role of these molecules this study is an important step towards unlocking the potential of IncRNA for rational genetic engineering of $\mathrm{CHO}$ cell lines.

\section{Materials and Methods}

\subsection{Cell culture, library preparation and RNA sequencing}

The cell culture protocol, profiling of extracellular metabolites, library preparation and RNA sequencing are described in detail in Tzani et al. 2019 (submitted to Biotechnology and Bioengineering).

\subsection{Data pre-processing, mapping and transcriptome assembly}

Raw read data was trimmed to remove low quality bases and adaptor contamination using cutadapt (Martin, 2011) v1.18 and Trimmomatic v0.36 (Bolger, Lohse, \& Usadel, 2014) and aligned to the ENSEMBL v98 CHOK1 reference genome using STAR v2.7.2d (Dobin et al., 2013). StringTie v2.0.3 (Pertea et al., 2015) (minimum junction coverage $=5$ ) was utilised to construct a genome guided transcriptome from the aligned RNASeq data. The transcripts per million (TPM) expression value was calculated using StringTie "-e" option.

\subsection{Long non-coding RNA annotation}

Transcriptome assembly filtering: Those transcripts intersecting a same strand exon of an annotated protein coding gene were removed from the transcriptome assembly using BEDtools v2.25.0 (Quinlan \& Hall, 2010).

LncRNA discovery, calculation of protein coding potential and classification: Long non-coding RNAs were initially identified following removal of transcripts $<200 \mathrm{bp}$ and followed by utilisation of the FEELnc software (Wucher et al., 2017). FEELnc was also used for initial classification of IncRNAs 
with respect to annotated protein coding genes. This classification was simplified into intergenic (>100kb from nearest protein coding genes), divergent (upstream antisense $\leq 2 \mathrm{~kb}$ from nearest), antisense (overlapping a protein coding gene), downstream antisense, upstream antisense, sense overlapping, upstream sense, downstream sense. Additional assessment of the likelihood of each transcript encoding a protein was performed using CPC2 v0.1 (Kang et al., 2017) and CPAT v1.2.4 (Wang et al., 2013).

Identification of potential open reading frames in IncRNAs: TransDecoder v5.5.0 (Haas et al., 2013) was used to translate open reading frames (ORFs) longer than 100 amino acids.

Comparison of candidate IncRNAs to RNA and protein databases: Nucleotide and transdecoder ORF protein sequences were searched against the SWISSPROT (UniProt Consortium, 2019) (release version, July 3, 2019), miRBase (Kozomara, Birgaoanu, \& Griffiths-Jones, 2019), RFAM (Kalvari et al., 2018) (IncRNA, snoRNA and Ribozyme) databases using BLAST. For all searches those hits with an expect value $<1 \times 10^{-5}$ were considered significant. In the case of RFAM snoRNA and ribozymes searches the BLAST percentage identify value was increased to $95 \%$.

Protein domain prediction: Protein domains in TransDecoder ORFs from candidate were predicted with hmmscan (Eddy, 2011) with the PfamA (El-Gebali et al., 2019). Pfam hits with an expect value < $1 \times 10^{-5}$ were considered significant.

Determination of CHO cell IncRNA synteny for human and mouse: To determine if IncRNA genes were syntenic for GENCODE annotated human (v32) and mouse IncRNA (v23) IncRNA sequences were first mapped to the UCSC CHO cell genome sequence (criGriChoV1) using the GMAP algorithm (Wu \& Watanabe, 2005). The UCSC genome browser (Haeussler et al., 2019) liftOver tool and prebuilt chain files linking the $\mathrm{CHOK} 1$ genome to human and mouse genomes were used to identify syntenic regions and subsequently GENCODE IncRNA annotations in the hg38 and mm10 genome assemblies.

\subsection{Differential expression analysis}

The number of RNASeq reads aligning to each gene in the (unfiltered) StringTie assembly was counted using HTSeq (Anders, Pyl, \& Huber, 2015) using strand-specific parameters. The DESeq2 (Love, Huber, \& Anders, 2014) method was used to identify differential expression between the NTS and TS sample groups $[27,28]$. Those IncRNA genes with a DESeq2 base mean $\geq 100$, an absolute 
fold change $\geq 1.5$ and a Benjamini-Hochberg adjusted $p$ value $<0.05$ were considered significantly differentially expressed.

\subsection{Reproducibility of the IncRNA annotation pipeline and RNASeq analysis}

Upon acceptance of this manuscript the code used to perform IncRNA annotation and differential expression analysis will be made freely available https://github.com/clarke-lab/cho cell IncRNA. The RNASeq data has been deposited to NCBI SRA (PRJNA593052).

\section{Acknowledgements}

The authors gratefully acknowledge funding from and Science Foundation Ireland (Grant references: 13/SIRG/2084, 15/CDA/3259 and H2020 Marie Sklodowska-Curie (Grant agreement No: 642663).

\section{References}

Anders, S., Pyl, P. T., \& Huber, W. (2015). HTSeq-A Python framework to work with high-throughput sequencing data. Bioinformatics, 31(2), 166-169. https://doi.org/10.1093/bioinformatics/btu638

Bolger, A. M., Lohse, M., \& Usadel, B. (2014). Trimmomatic: A flexible trimmer for Illumina sequence data. Bioinformatics, 30(15), 2114-2120. https://doi.org/10.1093/bioinformatics/btu170

Derrien, T., Johnson, R., Bussotti, G., Tanzer, A., Djebali, S., Tilgner, H., ... Guigó, R. (2012). The GENCODE v7 catalog of human long noncoding RNAs: Analysis of their gene structure, evolution, and expression. Genome Research, 22(9), 1775-1789. https://doi.org/10.1101/gr.132159.111

Dobin, A., Davis, C. A., Schlesinger, F., Drenkow, J., Zaleski, C., Jha, S., ... Gingeras, T. R. (2013). STAR: ultrafast universal RNA-seq aligner. Bioinformatics, 29(1), 15-21.

Eddy, S. R. (2011). Accelerated Profile HMM Searches. PLoS Computational Biology, 7(10), e1002195. https://doi.org/10.1371/journal.pcbi.1002195

El-Gebali, S., Mistry, J., Bateman, A., Eddy, S. R., Luciani, A., Potter, S. C., ... Finn, R. D. (2019). The Pfam protein families database in 2019. Nucleic Acids Research, 47(D1), D427-D432. https://doi.org/10.1093/nar/gky995

Fang, Y., \& Fullwood, M. J. (2016). Roles, Functions, and Mechanisms of Long Non-coding RNAs in Cancer. Genomics, Proteomics \& Bioinformatics, 14(1), 42-54. https://doi.org/10.1016/j.gpb.2015.09.006

Fischer, S., Handrick, R., \& Otte, K. (2015). The art of $\mathrm{CHO}$ cell engineering: A comprehensive retrospect and future perspectives. Biotechnology Advances, 33(8), 1878-1896. https://doi.org/10.1016/j.biotechadv.2015.10.015

Frankish, A., Diekhans, M., Ferreira, A.-M., Johnson, R., Jungreis, I., Loveland, J., ... Flicek, P. (2019). GENCODE reference annotation for the human and mouse genomes. Nucleic Acids Research, 47(D1), D766-D773. https://doi.org/10.1093/nar/gky955

Goyal, A., Fiškin, E., Gutschner, T., Polycarpou-Schwarz, M., Groß, M., Neugebauer, J., ... Diederichs, S. (2017). A cautionary tale of sense-antisense gene pairs: Independent regulation despite inverse correlation of expression. Nucleic Acids Research, 45(21), 1249612508. https://doi.org/10.1093/nar/gkx952

Haas, B. J., Papanicolaou, A., Yassour, M., Grabherr, M., Blood, P. D., Bowden, J., .. Regev, A. (2013). De novo transcript sequence reconstruction from RNA-seq using the Trinity platform for reference generation and analysis. Nature Protocols, 8(8), 1494-1512. https://doi.org/10.1038/nprot.2013.084

Haeussler, M., Zweig, A. S., Tyner, C., Speir, M. L., Rosenbloom, K. R., Raney, B. J., ... Kent, W. J. (2019). The UCSC Genome Browser database: 2019 update. Nucleic Acids Research, 47(D1), D853-D858. https://doi.org/10.1093/nar/gky1095

Kalvari, I., Argasinska, J., Quinones-Olvera, N., Nawrocki, E. P., Rivas, E., Eddy, S. R., .. Petrov, A. I. (2018). Rfam 13.0: Shifting to a genome-centric resource for non-coding RNA families. Nucleic Acids Research, 46(D1), D335-D342. https://doi.org/10.1093/nar/gkx1038 
bioRxiv preprint doi: https://doi.org/10.1101/863241; this version posted December 3, 2019. The copyright holder for this preprint (which was not certified by peer review) is the author/funder, who has granted bioRxiv a license to display the preprint in perpetuity. It is made available under aCC-BY-NC-ND 4.0 International license.

Kang, Y.-J., Yang, D.-C., Kong, L., Hou, M., Meng, Y.-Q., Wei, L., \& Gao, G. (2017). CPC2: A fast and accurate coding potential calculator based on sequence intrinsic features. Nucleic Acids Research, 45(W1), W12-W16. https://doi.org/10.1093/nar/gkx428

Kozomara, A., Birgaoanu, M., \& Griffiths-Jones, S. (2019). miRBase: From microRNA sequences to function. Nucleic Acids Research, 47(D1), D155-D162. https://doi.org/10.1093/nar/gky1141

Lewis, N. E., Liu, X., Li, Y., Nagarajan, H., Yerganian, G., O’Brien, E., ... Palsson, B. O. (2013). Genomic landscapes of Chinese hamster ovary cell lines as revealed by the Cricetulus griseus draft genome. Nature Biotechnology, 31(8), 759-765. https://doi.org/10.1038/nbt.2624

Liu, S. J., Horlbeck, M. A., Cho, S. W., Birk, H. S., Malatesta, M., He, D., ... Lim, D. A. (2017). CRISPRi-based genome-scale identification of functional long non-coding RNA loci in human cells. Science (New York, N.Y.), 355(6320). https://doi.org/10.1126/science.aah7111

Love, M. I., Huber, W., \& Anders, S. (2014). Moderated estimation of fold change and dispersion for RNA-seq data with DESeq2. Genome Biology, 15(12). https://doi.org/10.1186/s13059-0140550-8

Martin, M. (2011). Cutadapt removes adapter sequences from high-throughput sequencing reads. EMBnet.Journal, 17(1), 10-12. https://doi.org/10.14806/ej.17.1.200

Patrucco, L., Chiesa, A., Soluri, M. F., Fasolo, F., Takahashi, H., Carninci, P., ... Cotella, D. (2015). Engineering mammalian cell factories with SINEUP noncoding RNAs to improve translation of secreted proteins. Gene, 569(2), 287-293. https://doi.org/10.1016/j.gene.2015.05.070

Pertea, M., Pertea, G. M., Antonescu, C. M., Chang, T.-C., Mendell, J. T., \& Salzberg, S. L. (2015). StringTie enables improved reconstruction of a transcriptome from RNA-seq reads. Nature Biotechnology, 33(3), 290-295. https://doi.org/10.1038/nbt.3122

Quinlan, A. R., \& Hall, I. M. (2010). BEDTools: A flexible suite of utilities for comparing genomic features. Bioinformatics, 26(6), 841-842.

Rupp, O., MacDonald, M. L., Li, S., Dhiman, H., Polson, S., Griep, S., ... Lee, K. H. (2018). A reference genome of the Chinese hamster based on a hybrid assembly strategy. Biotechnology and Bioengineering, 115(8), 2087-2100. https://doi.org/10.1002/bit.26722

UniProt Consortium. (2019). UniProt: A worldwide hub of protein knowledge. Nucleic Acids Research, 47(D1), D506-D515. https://doi.org/10.1093/nar/gky1049

Uszczynska-Ratajczak, B., Lagarde, J., Frankish, A., Guigó, R., \& Johnson, R. (2018). Towards a complete map of the human long non-coding RNA transcriptome. Nature Reviews Genetics, 19(9), 535-548. https://doi.org/10.1038/s41576-018-0017-y

Vito, D., \& Smales, C. M. (2018). The Long Non-Coding RNA Transcriptome Landscape in CHO Cells Under Batch and Fed-Batch Conditions. Biotechnology Journal, 13(10), 1800122. https://doi.org/10.1002/biot.201800122

Wang, L., Park, H. J., Dasari, S., Wang, S., Kocher, J.-P., \& Li, W. (2013). CPAT: Coding-Potential Assessment Tool using an alignment-free logistic regression model. Nucleic Acids Research, 41(6), e74. https://doi.org/10.1093/nar/gkt006

Wu, T. D., \& Watanabe, C. K. (2005). GMAP: A genomic mapping and alignment program for mRNA and EST sequences. Bioinformatics (Oxford, England), 21(9), 1859-1875. https://doi.org/10.1093/bioinformatics/bti310

Wucher, V., Legeai, F., Hédan, B., Rizk, G., Lagoutte, L., Leeb, T., ... Derrien, T. (2017). FEELnc: A tool for long non-coding RNA annotation and its application to the dog transcriptome. Nucleic Acids Research, 45(8), e57. https://doi.org/10.1093/nar/gkw1306

Xu, X., Nagarajan, H., Lewis, N. E., Pan, S., Cai, Z., Liu, X., ... Wang, J. (2011). The genomic sequence of the Chinese hamster ovary (CHO)-K1 cell line. Nature Biotechnology, 29(8), 735-741. https://doi.org/10.1038/nbt.1932

\section{Supplementary Tables}

Table S1: Differentially expressed InRNA genelist. 400 IncRNA genes were found to be differentially expressed upon comparison of the NTS and TS sample groups. The IncRNA gene ID is shown (Ensembl or StringTie assigned) along with the baseMean of DESeq2 normalised counts, log2 p-value and BH adjusted p-value for each DE IncRNA gene. Where a IncRNA was found to overlap with GENCODE annotated IncRNA the human and/or mouse Ensembl ID and gene symbol are shown. For all non-intergenic IncRNAs the "best" FEELnc classified partner $\mathrm{CHO}$ protein coding gene Ensembl ID, Entrez ID and description are also provided. Where the partner protein coding gene was found to be differentially expressed the fold change and adjusted $p$-value calculated in Tzani et al. 2019 (submitted to Biotechnology \& Bioengineering).

Download link: https://app.box.com/s/4x00cj97teka5yu0w8itmsr48s6cz4ja 